\title{
Largest giant juvenile fibroadenoma of the breast
}

\author{
Shariful Islam, ${ }^{1}$ Sabrina Saroop, ${ }^{2}$ Vinoo Bheem, ${ }^{1}$ Vijay Naraynsingh ${ }^{3}$
}

${ }^{1}$ Specialised Breast Surgeon, Department of Surgery, San Fernando General Hospital, San Fernando, Trinidad and Tobago ${ }^{2}$ Department of Clinical Surgical Science, University of the West Indies, St Augustine, Trinidad and Tobago

${ }^{3}$ University of the West Indies, St Augustine, Trinidad and Tobago

Correspondence to Dr Shariful Islam, sss1201198@yahoo.com

Accepted 7 December 2018

Check for updates

(C) BMJ Publishing Group Limited 2019. No commercial re-use. See rights and permissions. Published by BMJ.

To cite: Islam S, Saroop S, Bheem V, et al. BMJ Case Rep 2019;12:e227277. doi:10.1136/bcr-2018227277

\section{SUMMARY}

Juvenile giant fibroadenoma is a rare benign tumour of the breast accounting for $0.5 \%$ of all fibroadenomas. The presentation can be very dramatic and may result in breast deformity and may mimic a rare malignant tumour. It is indeed a great challenge to provide the best treatment for these patients in terms of clinical and psychological care. Meticulous surgical planning is required to ensure a fine balance between adequate resection and the best cosmetic outcome for a developing breast. Every effort should be made to preserve the developing breast irrespective of the size of the tumour as it is in this case. We report the world's largest juvenile fibroadenoma of the breast in a 16-yearold girl who presented to our hospital with a $28 \times 25 \mathrm{~cm}$ mass on her left breast in which breast conservation was done. A detailed literature search and management of these lesions are discussed.

\section{BACKGROUND}

Breast cancer is the most common malignancy among women worldwide. There has been a recent focus on breast cancer affecting young women and so younger women are now more likely to seek medical assessment of breast lumps. This being said, fibroadenomas still remain the most common tumour among women less than 30 years. Other differentials include lipomas, phyllodes tumour and hamartomas. Fibroadenomas can present in various sizes. When they present as large swellings, with a history of sudden expansion, it is particularly worrisome. The exact aetiology of this giant fibroadenoma is unknown; however, hormonal influence may have been postulated.

\section{CASE PRESENTATION}

We present a case of a 16-year-old girl who was referred to the surgical outpatient clinic with a left breast lump noticed about 1 year before with sudden expansion over a 5 -month period. It was painful on movement but there were no other associated symptoms. She had no known family history of breast or ovarian cancers. Menarche was at 13 years and regular. The patient denied any sexual activity. There was no history of using oral contraceptives or chest wall radiation. On examination she was found to have obvious asymmetry of the breasts with the left being significantly larger. There was a $28 \times 25 \mathrm{~cm}$ firm swelling on the left breast occupying the entire outer quadrants of the left breast. There were distended superficial veins. No nipple abnormalities, peau d'orange or lymphadenopathy was found (figure 1). The examination of the right breast was normal.

\section{INVESTIGATIONS}

Ultrasound scan showed a solid, hypoechoic lesion in the left breast. A core biopsy was done of the left side which confirmed the lump to be a fibroadenoma.

\section{DIFFERENTIAL DIAGNOSIS}

Giant juvenile fibroadenoma, phyllodes tumour, lipomas and physiologic hyperplasia hamartoma, adenocarcinoma, and pseudoangiomatous stomal hyperplasia

\section{TREATMENT}

After extensive counselling of the patient and her parents a decision was made for complete excision or enucleation of the lump. Written consent was obtained from the parents for the procedure as well as to obtain intraoperative and postoperative photographs. Under general anaesthesia, with aseptic technique an axillary incision was made (figure 2). The lump was excised completely with ligation of the grossly dilated blood vessels (figure 3). Meticulous homoeostasis was achieved. A large cavity was noted after removal of the left lump (figure 4). The size of the fibroadenoma was measured as $28 \times 25 \mathrm{~cm}$ (figures $5 \mathrm{~A}, \mathrm{~B}$ and $6 \mathrm{~A}, \mathrm{~B}$ ). A Vacuum assisted closure (VAC) drain was placed in situ and the wound was closed subcuticularly with 3-0 vicryl rapid (figure 7).

\section{OUTCOME AND FOLLOW-UP}

The patient had a successful postoperative recovery and was discharged home on the second

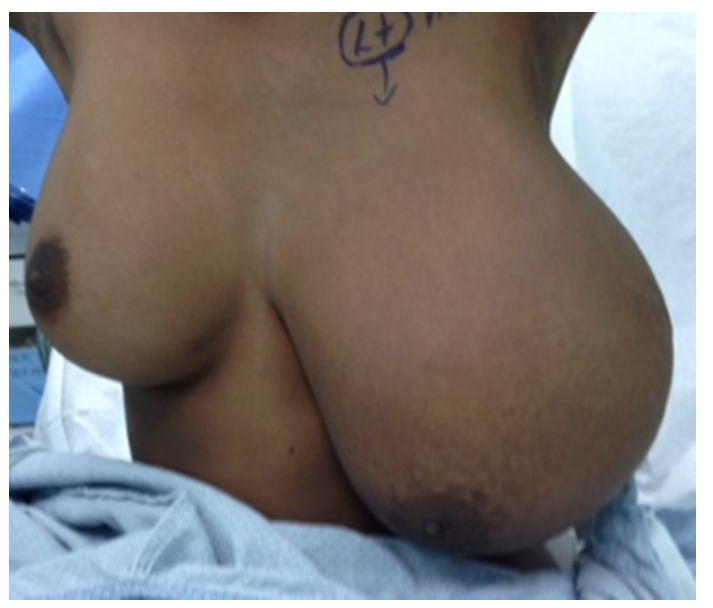

Figure 1 Showing a large mass on the left breast occupying entire outer quadrants of the left breast with distended superficial veins. 


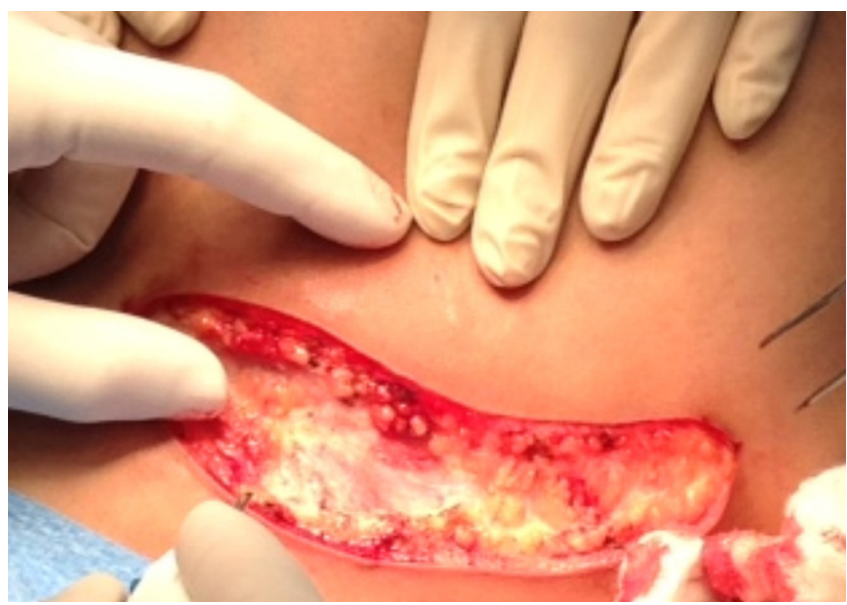

Figure 2 Showing left axillary incision for the removal of the giant fibroadenoma.

postoperative day. Histology of the lump was confirmed as fibroadenoma, in keeping with the original biopsy (figure 8

She is now at 9 months postoperation and is unlikely to need any further procedures with regard to the skin laxity (figure 9). As she is yet to complete her secondary sexual development, it is unwise to make any final assessments at this point in time and she will continue to receive follow-up until a final decision is made.

\section{DISCUSSION}

Fibroadenomas are among the most common tumours found in women. Most common in those less than 30 years. It is a benign condition which is divided into adult-type and juvenile-type fibroadenomas. The juvenile type is limited to the age group

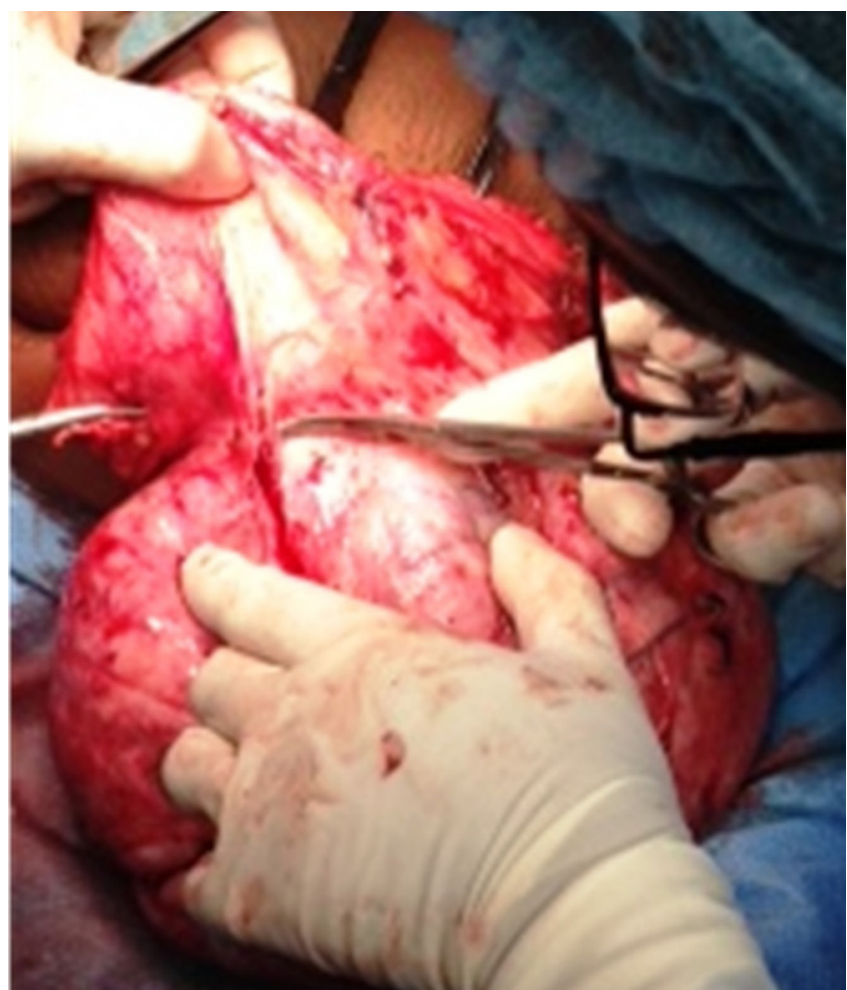

Figure 3 Ligation of the dilated vessels to achieve meticulous haemostasis.

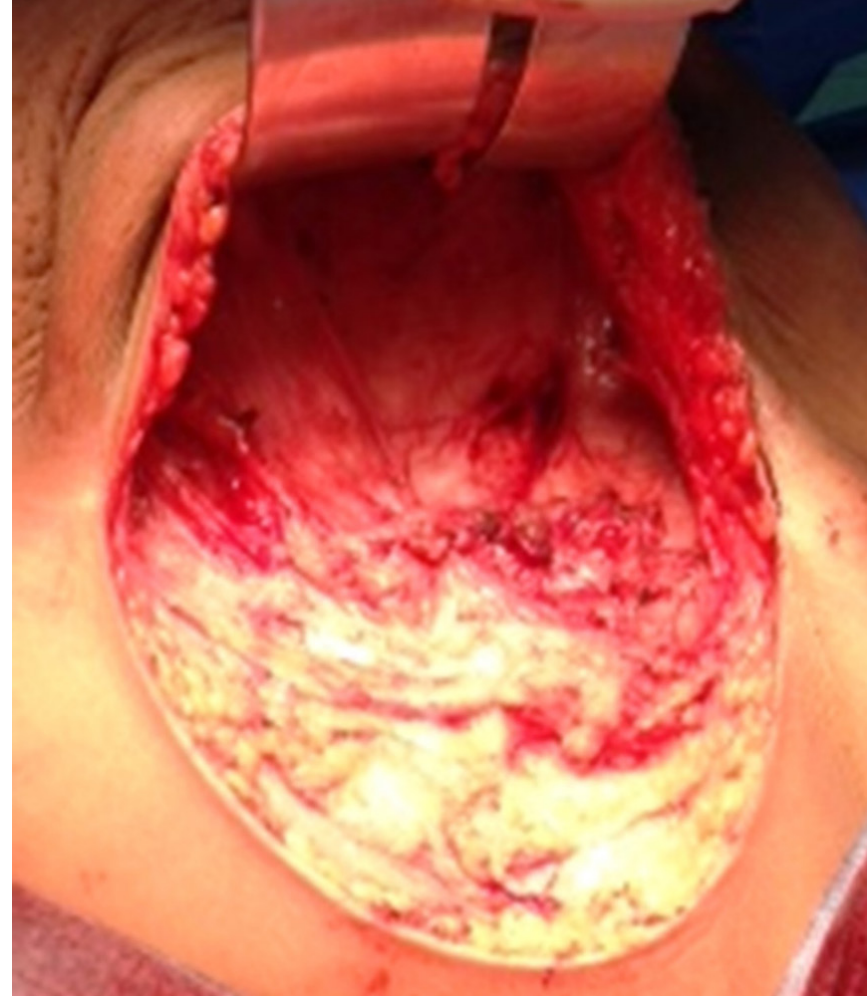

Figure 4 Showing the huge cavity left after excision of the giant fibroadenoma.

between 10 and 18 years. It has a typical benign stromal and epithelial pattern on histological examination which is subdivided into pericanalicular or intracanalicular types. ${ }^{1}$ It is thought to be an aberration of normal development. Although it is a benign condition, neoplasia can form from the stromal elements within it. The risk is thought to be 3\% and more likely if the fibroadenoma is associated with sclerosing adenosis, papillary apocrine changes, calcifications or cysts. It is often detected as a smooth, firm, mobile breast lump without associated lymphadenopathy. A giant fibroadenoma is a specific type of fibroadenoma which weighs $>500 \mathrm{~g}$ or measures $>5 \mathrm{~cm}$ on diameter or is disproportionally large compared with the rest of the breast. Most giant fibroadenomas are unilateral, however bilateral giant juvenile fibroadenomas are also reported. ${ }^{2-5}$ The size of the giant fibroadenoma varies from $5 \mathrm{~cm}$ to as high as $23 \mathrm{~cm}$, with a mean lesion size of $11.2 \mathrm{~cm} .{ }^{6}$ Only two cases of juvenile giant fibroadenoma were documented as $20 \mathrm{~cm}$ one by K Gaurav et al in $2015(20 \times 20 \mathrm{~cm})^{7}$ and the other by U Celik at al in 2017
A

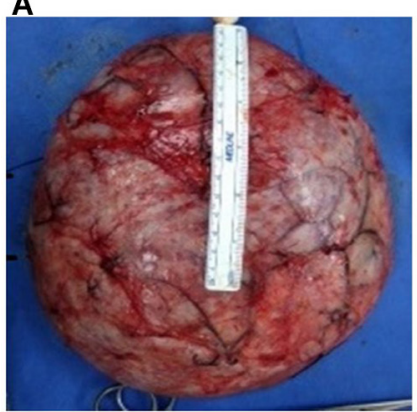

B

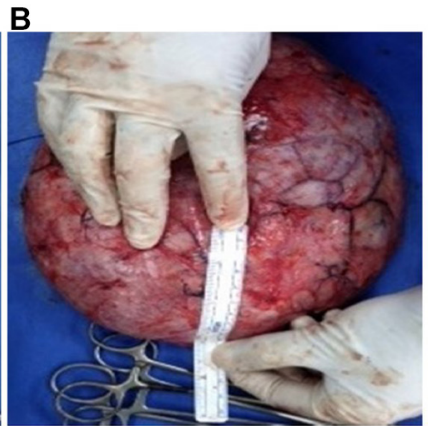

Figure 5 (A-B) Postoperative longitudinal measurement of the gross specimen. 


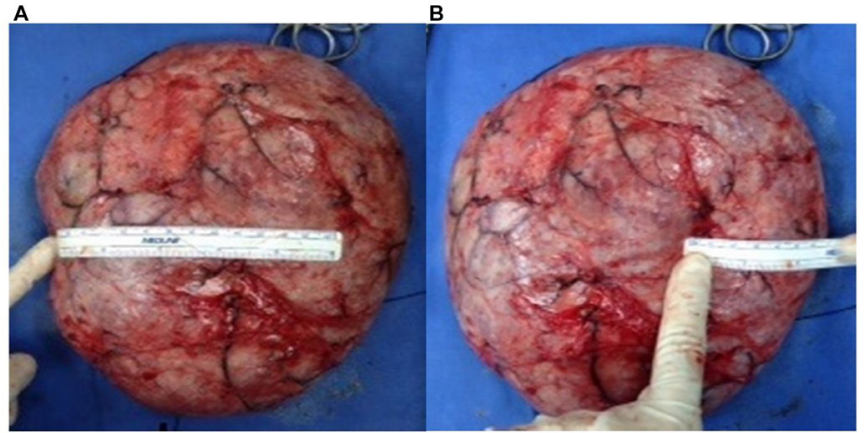

Figure $6(A, B)$ Postoperative transverse measurement of the gross specimen.

$(20 \times 15 \mathrm{~cm}) .{ }^{8}$ However giant juvenile fibroadenoma greater than $20 \mathrm{~cm}$ is extremely rare. Literature search has revealed only two such cases, one juvenile and one adult type of giant fibroadenoma. The largest juvenile giant fibroadenoma is reported in a 15 -year-old woman diagnosed in her 14th week of gestation and measured as $22 \times 19 \mathrm{~cm},{ }^{9}$ on the other hand the largest adult giant fibroadenoma was reported in a 22 -year-old woman and measured as $23 \times 28 \mathrm{~cm}^{10}$

The main differentials for this condition are cysto-phyllodes tumours, lipomas and physiological hyperplasia and other rare differentials such as hamartoma, pseudoangiomatous stomal hyperplasia, adenocarcinoma and macrocyst. ${ }^{11}$

It is important to differentiate it from a phyllodes tumour in the preoperative stage as the surgical approach and implications for prognosis is vastly different. In this regard, only histological examination via a core biopsy can do this. Fine needle aspiration has not been shown to be adequate for diagnosis. ${ }^{12} 13$

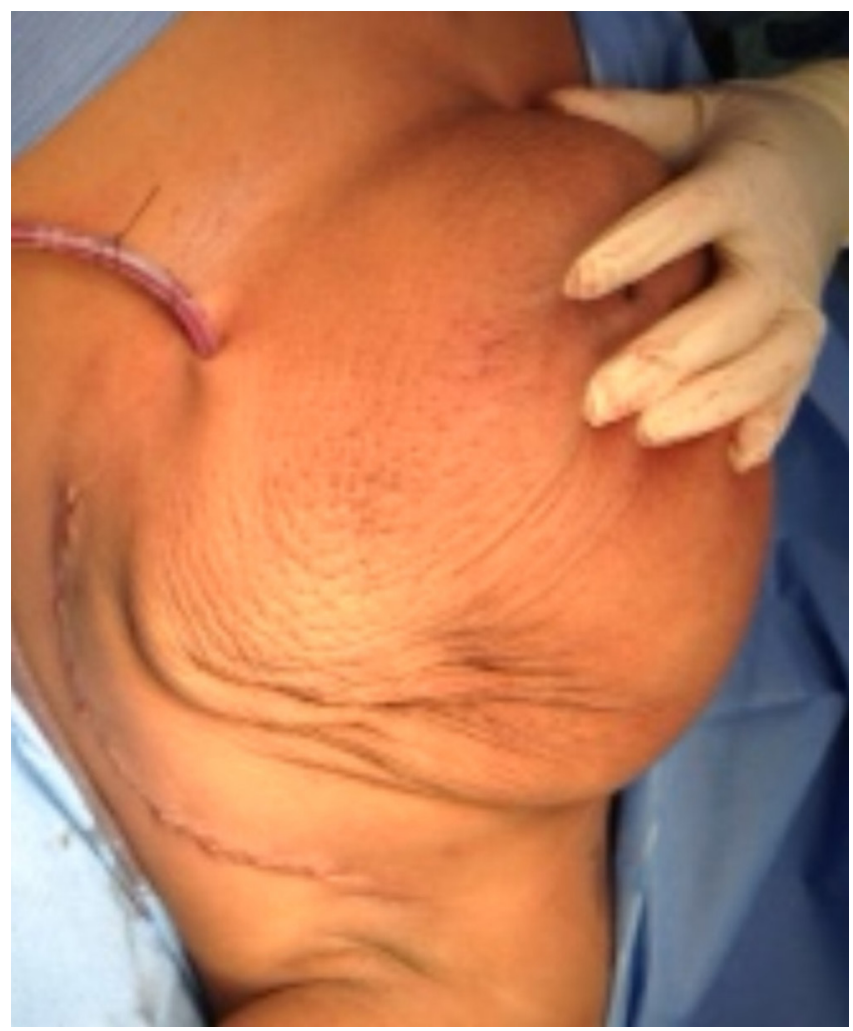

Figure 7 Showing immediate postoperative appearance of the breast after the closure of the skin.
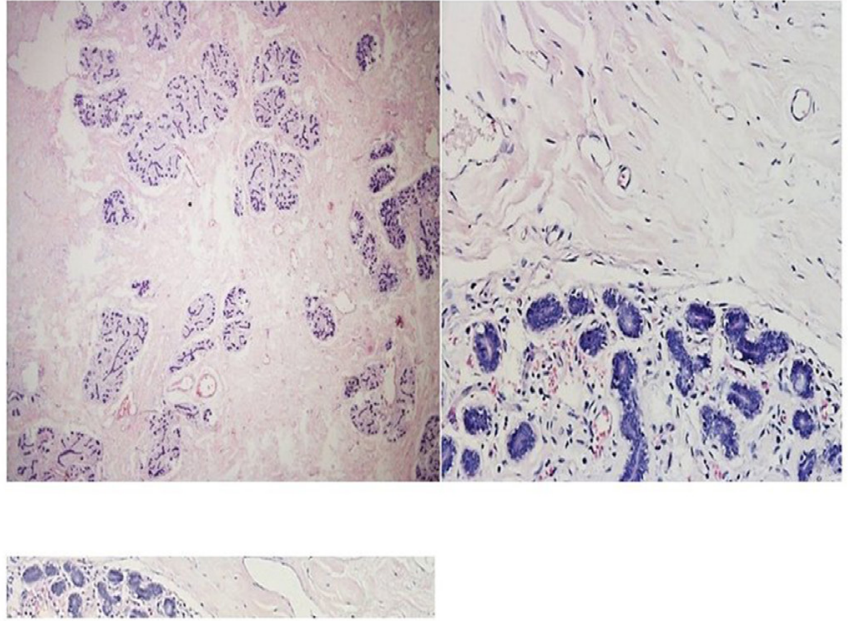

Figure 8 Showing a well demarcated lesion with both cellular and stromal elements and there is no cellular atypia or mitoses.

Radiological imaging from the traditional ultrasound scans and mammograms to sophisticated non-contrast and dynamic contrast enhanced MRI's have not been shown to be able to definitely differentiate the two. ${ }^{14}$

Once confirmed to be a fibroadenoma, simple excision can be undertaken. However, the approach to these giant tumours can be far from simple as their massive size and subsequent architectural distortion can make for a difficult cosmetic outcome. There is no uniform surgical approach for these tumours. The treatment options are heterogeneous and varied, from simple enucleation to mastectomy with or without immediate or delayed breast reconstruction. ${ }^{6}$ The type of incision is also varied from a circumareolar or a submammary incision and incision directly over the lump. ${ }^{15}$ Lim et al developed a new surgical algorithm by using preoperative imaging to predict cosmetic outcomes of the mammoplasty for large non-malignant tumours. He reported a good to excellent cosmetic outcomes in all the patients with an estimated tumour to breast size ratio up to $70 \% .{ }^{15}$ Different oncoplastic techniques have also been described in the management of these tumours that is, vertical, wise pattern and round block techniques.

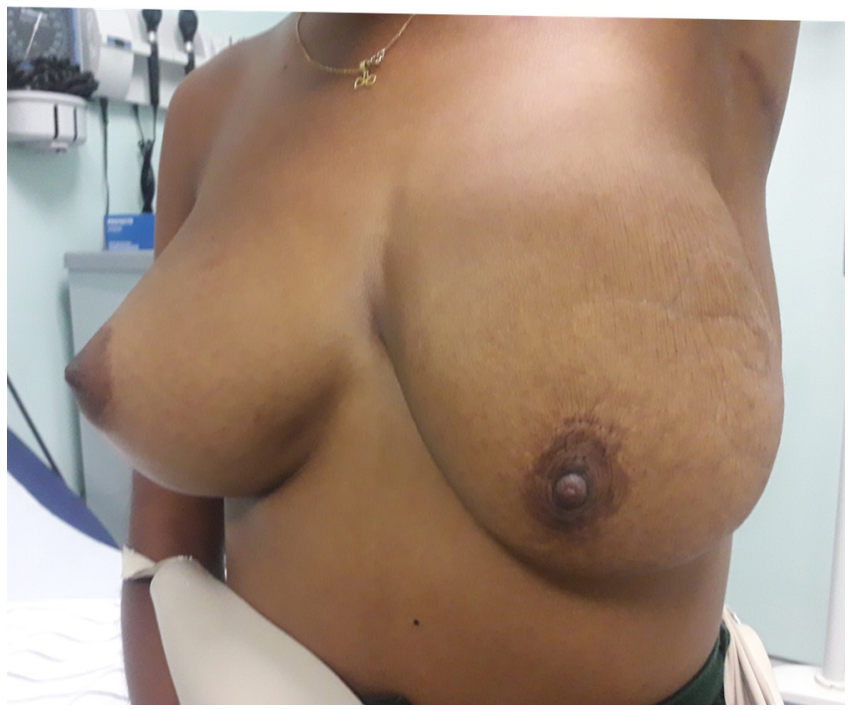

Figure 9 Photograph of the breast at 9 months' follow-up showing near normal appearance of the breast. 
However, the key concern in these patients is to leave the breast with minimal or no scar. Even a simple scar on the breast in these adolescence patients can have a strong psychological impact. In fact, it can traumatise these patients every moment they look at themselves. Surgeons must therefore, carefully plan the position of their incision to allow complete removal of the tumour without unnecessary scarring. In our patient we used an axillary incision to remove the tumour. The use of an axillary incision is less likely to produce a keloid scar compared with incisions approaching the midline. We believe this incision is appropriate for any giant tumour located in the outer quadrants of the breast and especially when it is difficult to remove via a circumareolar incision. A submammary incision is a good choice of incision for both the ptotic and non-ptotic breasts. ${ }^{6}$ However it is best suited for ptotic breasts as any degree of ptosis will hide this scar. The axillary incision on the other hand is usually hidden in the arm pit, hence it is cosmetically more appealing and there is no obvious scar on the breast compared with the other incisions.

Patients must be adequately counselled about the postoperative expectations. There is often some gain in skin elasticity by about 6 months postoperative, so patience is the key before one embarks on unnecessary reconstructive procedures. ${ }^{16}$ Also, as these patients are often still undergoing puberty, this must be taken into consideration too. Long-term follow-up is necessary in these patients as there are reports of recurrence of this tumour. ${ }^{17}$

\section{Patient's perspective}

I was very much concerned for my daughter as the mass was growing very rapidly in her breast. I was also worried about the postoperative scar on her breast. However, the doctors were very professional and explained every possibility in detail with the assurance of best care. My daughter and I are very thankful to the Lord and the doctors that they were able to remove the tumour successfully without having to do mastectomy and there is no obvious scar on her breast.

Our stresses have been relieved after receiving the final histopathology report. Finally, I am happy to see that, slowly her breast shape is also taking the near normal shape like her other breast.

\section{Learning points}

- Giant fibroadenoma is an important differential diagnosis to consider in adolescent females a with rapidly growing breast lump.

- Differentiating giant fibroadenoma from phyllodes tumours is often clinically difficult, therefore needle core biopsy or surgical excision is highly recommended to confirm the diagnosis.

- Simple surgical excision is highly recommended with preservation of normal breast tissue and the nipple areolar complex to allow normal breast tissue to grow. Mastectomy should be avoided at any cost.

- Incision should be chosen based on their best postoperative cosmetic appearance rather than at the surgeon's convenience.

- The use of an axillary incision is less likely to produce a keloid scar compared with incisions approaching the midline.
With this report we present the world's largest giant juvenile fibroadenoma in a 16-year-old girl. The tumour was removed successfully by enucleation via an axillary incision with preservation of the normal breast tissue and nipple areolar complex.

\section{CONCLUSION}

Fibroadenoma is the most common breast pathology in females less than 30 years. They can grow to a very large size, prompting the need for early surgical excision. They should be differentiated from phyllodes tumour prior to definitive surgery. Surgery involves careful planning before excision and after with respect to need for reconstruction. Mastectomy should be avoided at any cost. Along with circumareolar, submammary incision, axillary incision can be a good choice of incision for the giant fibroadenomas located in the outer quadrants of the breast.

Acknowledgements The authors do acknowledge Dr. Dawn William of pathology department of San Fernando General Hospital for her contribution in her reading and supplying the histo-micrographs of this case.

Contributors SI, SS, VB have helped in collecting data, designing and helped in discussion and writing up the manuscript. VN has helped in writing and critically analyzing the manuscript.

Funding The authors have not declared a specific grant for this research from any funding agency in the public, commercial or not-for-profit sectors.

Competing interests None declared.

Patient consent Obtained.

Provenance and peer review Not commissioned; externally peer reviewed.

\section{REFERENCES}

1 Kempson RL, Rouse RV. Juvenile Fibroadenoma of the BreastStanford school of medicine. http://surgpathcriteria.stanford.edu/breast/juvfibroadenoma/.

2 Mukhopadhyay M, Patra R, Mondal S, et al. Bilateral giant juvenile fibroadenoma of breasts. J Indian Assoc Pediatr Surg 2009;14:68-9.

3 Kaur N, Saini S, Somasekhar S, et al. Bilateral florid juvenile fibroadenomas of the breast in an adolescent: a rare indication for subcutaneous mastectomy. J Pediatr Adolesc Gynecol 2015;28:e135-e137.

4 Lee CJ, Kim YJ, Seo YT, et al. Treatment of multiple bilateral juvenile fibroadenomas in a teenage breast by central pedicle breast reduction, with vertical and short horizontal scar: case report. Aesthetic Plast Surg 2004;28:228-30.

5 Nikumbh DB, Desai SR, Madan PS, et al. Bilateral giant juvenile fibroadenomas of breasts:a case report. Patholog Res Int 2011;2011:1-4.

6 Sosin M, Pulcrano M, Feldman ED, et al. Giant juvenile fibroadenoma: a systematic review with diagnostic and treatment recommendations. Gland Surg 2015;4:312-21.

7 Gaurav K, Chandra G, Neelam K, et al. A pre-pubertal girl with giant juvenile fibroadenoma: A rare case report. Int J Surg Case Rep 2015;16:87-9.

8 Celik SU, Besli Celik D, Yetiskin E, et al. Giant juvenile fibroadenoma of the breast: a clinical case. Arch Argent Pediatr 2017;115:e428-e431.

9 Moghimi M, Soltani HR, Zarch MB. Giant juvenile fibroadenoma presenting in a 15-year-old pregnant woman: a case report. J Ped Hematol Oncol 2017;7:130-2.

10 McCague A, Davis JV. Giant fibroadenoma in a 22 year old patient: case report and literature review. Breast Dis 2010;31:49-52.

11 Shah NM, Pandya NR, Dalal PR, et al. Giant fibroadenoma: Mimicking a phylloides tumor. GMJ;64.

12 Kapila K, Pathan SK, Al-Mosawy FA, et al. Fine needle aspiration cytology of breast masses in children and adolescents: experience with 1404 aspirates. Acta Cytol 2008;52:681-6.

13 Homesh NA, Issa MA, El-Sofiani HA. The diagnostic accuracy of fine needle aspiration cytology versus core needle biopsy for palpable breast lump(s). Saudi Med J 2005;26:42-6

14 El Khouli RH, Louie A. Case of the season: a giant fibroadenoma in the guise of a phyllodes tumor; characterization role of MRI. Semin Roentgenol 2009;44:64-6.

15 Lim GH, Ng RP, Leong LCH. Development of a surgical algorithm by using preoperative imaging to predict mammoplasty cosmetic outcomes for large nonmalignant tumours. Gland Surg 2017;6:649-53.

16 Sosin M, Feldman E. Giant juvenile fibroadenoma: a case and review of novel modalities in treatment. Breast Dis 2012;34:35-8.

17 Huang IC, Li PC, Ding DC. Recurrent juvenile fibroadenoma of the breast in an adolescent: a case report. Medicine 2018;97:e10765. 
Copyright 2019 BMJ Publishing Group. All rights reserved. For permission to reuse any of this content visit https://www.bmj.com/company/products-services/rights-and-licensing/permissions/

BMJ Case Report Fellows may re-use this article for personal use and teaching without any further permission.

Become a Fellow of BMJ Case Reports today and you can:

- Submit as many cases as you like

- Enjoy fast sympathetic peer review and rapid publication of accepted articles

Access all the published articles

- Re-use any of the published material for personal use and teaching without further permission

For information on Institutional Fellowships contact consortiasales@bmjgroup.com

Visit casereports.bmj.com for more articles like this and to become a Fellow 